\title{
Modelling multiple outcomes to improve the detection of causal mediation effects in complex intervention trials
}

\author{
Neil Casey', Simon Thompson ${ }^{1,2}$, Andrew T Prevost ${ }^{1,3^{*}}$ \\ From Clinical Trials Methodology Conference 2011 \\ Bristol, UK. 4-5 October 2011
}

\begin{abstract}
Aim
In a trial to increase physical activity in sedentary adults, there was no evidence of effect on the primary outcome, though large significant effects amongst eight related SF36 measures of general health [1]. How could such differences arise? Could they be: a true effect mediated through receiving the intervention, another systematic effect such as self-reporting bias, and/or chance? The aim was to develop reliable methods to investigate whether effects of the intervention on the SF36 outcomes were mediated through truly receiving the intervention delivered in intervention sessions.
\end{abstract}

\section{Methods}

We adopted a structural mean modelling approach with a two-stage least-squares estimation algorithm, in order to estimate mediation effects free from confounding bias [2]. It involves predicting the mediator (number of sessions attended), and outcomes, from baseline covariates. Each individual has a personal predicted 'counterfactual' treatment-effect difference which is regressed on the predicted mediator using a dose-response model. Although reliably bias-free, typically these methods do not provide sufficiently precise estimates except for the simplest of models. A simulation study was designed to establish the factors driving the lack of precision. We extended the two-stage approach, using linear mixed effects and GEE modelling to enable multiple SF36 outcomes to contribute to estimation of a common mediation effect.

\footnotetext{
* Correspondence: toby.prevost@kcl.ac.uk

${ }^{1}$ Department of Public Health and Primary Care, University of Cambridge, CB2 OSR, UK

Full list of author information is available at the end of the article
}

\section{Results}

In this trial, attendance at sessions was invariably high, adversely affecting the precision of the estimates. From the simulation study, important factors affecting detection were identified to be the size of the trial effect and the degree to which the mediator is predictable from baseline covariates. The effect of analysing four SF36 outcomes to estimate an assumed common mediation effect was to reduce the standard error of the estimated effect by up to $40 \%$, equivalent to offering an increase in power to detect mediation from $50 \%$ to $80 \%$. The mediation effect was statistically significant.

\section{Conclusions}

The extension of bias-free estimation of a mediation effect from one to multiple related outcomes offered an appreciable improvement in the power to detect mediation effects and to estimate them more precisely. The significant effect through sessions indicates that some of the effect may well be genuinely connected with receipt of intervention material. The approach requires assumptions.

\section{Author details}

${ }^{1}$ Department of Public Health and Primary Care, University of Cambridge, CB2 OSR, UK. ${ }^{2}$ Medical Research Council Biostatistics Unit, Institute of Public Health, Cambridge, CB2 OSR, UK. ${ }^{3}$ Department of Primary Care and Public Health Sciences, King's College London, SE1 3QD, UK.

Published: 13 December 2011

\section{References}

1. Kinmonth AL, Wareham NJ, Hardeman W, Sutton S, Prevost AT, Fanshawe T, Williams KM, Ekelund U, Spiegelhalter D, Griffin SJ: Efficacy of a theorybased behavioural intervention to increase physical activity in an at-risk group in primary care (ProActive UK): a randomised trial. Lancet 2008, 371:41-48. 
2. Dunn G, Bentall R: Modelling treatment-effect heterogeneity in randomized controlled trials of complex interventions (psychological treatments). Stat Med 2007, 26:4719-4745.

doi:10.1186/1745-6215-12-S1-A146

Cite this article as: Casey et al:: Modelling multiple outcomes to improve the detection of causal mediation effects in complex intervention trials. Trials 2011 12(Suppl 1):A146.

Submit your next manuscript to BioMed Central and take full advantage of:

- Convenient online submission

- Thorough peer review

- No space constraints or color figure charges

- Immediate publication on acceptance

- Inclusion in PubMed, CAS, Scopus and Google Scholar

- Research which is freely available for redistribution

Submit your manuscript at www.biomedcentral.com/submit
() Biomed Central 